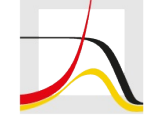

MAX PLANCK INSTITUTE

FOR DEMOGRAPHIC RESEARCH

Konrad-Zuse-Strasse 1 · D-18057 Rostock · Germany · Tel +49 (0) 3812081 - 0 · Fax +49 (0) 3812081 - $202 \cdot$ www.demogr.mpg.de

MPIDR Working Paper WP 2022-001 I January 2022

https://doi.org/10.4054/MPIDR-WP-2022-001

\title{
Disparities in the population burden of joint cognitive and physical impairment in the US, 1998-2016
}

Shubhankar Sharma I sharma@demogr.mpg.de Jo Mhairi Hale Mikko Myrskylä

Hill Kulu 
Disparities in the population burden of joint cognitive and physical impairment in the US, 1998-2016

Shubhankar Sharma, MPhil 1,2, Jo Mhairi Hale, PhD 1,2, Mikko Myrskylä, PhD 1,3, Hill Kulu, $\mathrm{PhD}^{2}$

${ }^{1}$ Lab of Population Health, Max Planck Institute for Demographic Research, Germany.

${ }^{2}$ School of Geography \& Sustainable Development, University of St Andrews, Scotland.

${ }^{3}$ Department of Social Research, University of Helsinki, Finland. 


\section{Abstract}

Although cognitive and physical impairments often co-occur in older individuals, they are typically studied as separate outcomes. Using the Health and Retirement Study (1998-2016) and multistate models, we quantify the population burden of their co-occurrence (joint impairment) using two key indicators- lifetime risk and expectancy, by gender, race/ethnicity/nativity, education and their interactions for Americans aged 50 and over. Furthermore, we analyze what fraction of the racial/ethnic inequalities in joint impairment is attributable to inequalities in educational attainment. Results reveal that $58 \%$ of women and $42 \%$ of men aged 50 are predicted to experience joint impairment in their remaining life expectancy. Women also live longer in joint impairment than men (3.4 vs 1.9 years). Foreign-born Latinas have $83 \%$ lifetime risk compared with Whites' $52 \%$ and three times more jointly impaired years. Lower educated men experience 32 percentage points higher lifetime risk and three times more joint impairment years than higher educated men. The lowest educated Blacks and Latinx carry the greatest joint impairment burden. This study emphasizes the importance of considering cognitive and physical impairment simultaneously in assessing older-age disability. The finding that up to $74 \%$ of the racial/ethnic disparities are attributable to inequalities in educational attainment can inform policy.

Keywords: Health disparities, cognitive impairment, physical impairment, lifetime risk, health expectancy. 


\section{Introduction}

With lengthening of life expectancies, maintaining health and well-being of older individuals has become a public health priority in higher-income countries. Prior studies have assessed older age health impairments, such as cognitive or physical impairment, as separate health outcomes (Crimmins et al. 2016; Freedman and Spillman 2016; Ostchega et al. 2000; Reuser et al. 2011; Zaninotto et al. 2020). Recent evidence, however, suggests the importance of studying disability from the perspective of simultaneous cognitive and physical impairment. Co-occurrence of these impairments has greater ramifications on the affected adults as well as on their caregivers compared with the consequences from single domain impairment (Riffin et al. 2017).

This study is the first to quantify the population burden of disability related to the simultaneous occurrence of cognitive and physical impairment (joint impairment) and contributes to population health research in four key ways. First, using the Health and Retirement Study, a high-quality panel survey representative of Americans aged 50 and over, we estimate two key indicators: 1) lifetime risk of ever experiencing joint impairment, and 2) number of years expected to live jointly impaired. These indicators can help us gain an understanding of the burden of joint impairment in older US population. Second, we investigate how this burden differs by intersecting life-course (dis)advantages, including gender, race/ethnicity/nativity, and education. Identifying the subpopulations with greater burden will also help to identify the caregiver subgroups who are at higher risk of poor health due to bearing a substantial caregiving burden. Third, we examine what fraction of the 
disparities in joint impairment are attributable to educational inequalities by estimating a counterfactual that eliminates racial/ethnic inequalities in the distribution of educational attainment.

The majority of the health research exploring the burden of disability has applied the Sullivan method (Crimmins et al. 2016; Freedman and Spillman 2016; Garcia et al. 2019; Suthers et al. 2003). This approach is based on disability prevalence, which reflects a portion of the past risk of impairment in the population. The method does not allow recovery from disability, nor does it allow mortality to vary by health status. In contrast, the multistate method relies on incidence data, which is a measure of current risk of impairment in the population. It allows recovery (e.g., transition back from disability to healthy when one recovers from an illness that inhibits ADLs or cognitive function) and allows mortality to vary by different health states considered. In sum, the multistate approach helps to estimate contemporary population health dynamics more accurately. Therefore, we address our novel objectives using preferred incidence-based discrete-time Markov chain multistate models.

\section{Background}

Older age life expectancy has increased in the US in recent decades (WHO 2017). This increased life expectancy has contributed to the expansion of older population. For instance, adults aged 65 and over constituted 17\% (56 million) of the total US population in 2020 (Vespa et al. 2018). By 2040, the share of older adults will escalate to $22 \%$ (81 million). Population aging poses a challenge as cognitive and physical function decline as adults age, often preventing independent living. 
Over 6 million older Americans are affected by severe cognitive impairment and limitations in physical activities translate into a loss of 432,224 years of healthy life for older Americans (McGrath et al. 2019; Rajan et al. 2019). Findings from recent longitudinal analyses indicate a significant rise in the prevalence of cognitively and physically impaired older Americans in recent decades (Hale et al. 2020; Wang et al. 2021). One study identified over 1 million community-dwelling Americans aged 65 and over experiencing the co-occurrence of cognitive and physical impairment (Riffin et al. 2017). Although extensive research has been carried out on the individual impact of cognitive and physical impairment, there exists no study that estimates the lifetime risk of and expectancies in both of these impairments, which is likely to be a highly disadvantaged health state.

There is an urgent need to address the burden of joint impairment in health research, as the number of adults affected by joint impairment is likely to increase. First, both cognitive and physical impairments share common risk factors, such as age and a range of morbidities like diabetes, stroke, hypertension (Caskie et al. 2010; Crichton et al. 2016; Hankey et al. 2002; Langa et al. 2017; Skoog and Gustafson 2006; Verruca et al. 1996; Wong et al. 2013). The burden of these morbidities is projected to grow in coming years in the US (Heidenreich et al. 2011; Lin et al. 2018; Ovbiagele et al. 2013). For instance, the prevalence of diabetic adults aged 65 and over is projected to increase from 9.2 million in 2014 to 35.2 million by 2060 (Lin et al. 2018). Second, cognitive impairment is itself a significant risk factor of physical disability (Hajek and König 2016; Sauvaget et al. 2002) and the number of older adults with dementia is projected to be more than double (14 million) by 2060 (Rajan et al. 
2019). All of these factors, in addition to the substantial increase in the share of adults in the high-risk older ages, are likely to increase joint impairment cases.

Cognitive and physical disability exert considerable burden on the affected adults, lower quality of life, and increase risk of death (Alzheimer's Association 2021; Ankuda et al. 2020; Gobbens 2018; Langa et al. 2008). Compared with single domain impairment, joint impairment is more detrimental for independent living, as the compounding of impairments means greater dependence on caregivers to support daily activities (Riffin et al. 2017). The percentage of caregivers reporting physical, emotional, and financial difficulties and limitations in social-participation associated with care provision are highest for caregivers of jointly impaired adults, compared with the caregivers of adults with only cognitive or physical impairment (Riffin et al. 2017), which are associated with adverse health consequences (Fratiglioni et al. 2000).

Exacerbating caregiving challenges, the burden of these health impairments is not uniform across the US population. For instance, more women than men are cognitively and physically impaired, and they also spend more years in these impairments than men (Calenti et al. 2010; Crimmins et al. 2016; Hale et al. 2020; Suthers et al. 2003; Zaninotto et al. 2020). Compared with Whites, Blacks and Latinx (both US-and foreign-born) have significantly higher odds of cognitive impairment and poorer cognitive health expectancies, net of education and other health conditions (Garcia et al. 2019; Reuser et al. 2011). These subpopulations also have higher risk of disability and have longer disability expectancies compared with Whites (Freedman and Spillman 2016; Garcia et al. 2017; Ostchega et al. 
2000; Zsembik et al. 2000). Lower-educated older adults have significantly higher risk of cognitive impairment (Reuser et al. 2011) and disability (Carmona-Torres et al. 2019), net of other socio-demographic risk factors, and live longer in cognitive and physical impairment (Crimmins and Saito 2001; Crimmins et al. 2018; Lièvre et al. 2008; Zaninotto et al. 2020). Moreover, among racial/ethnic sub-groups, those with lower education live a greater proportion of their lives in cognitive and physical impairment compared with their highly educated counterparts (Crimmins et al. 1996; Farina et al. 2020; Guralnik et al. 1993). However, the burden of joint impairment for these subpopulations has yet to be studied.

The significant variations in cognitive and physical health among Whites, Blacks, and Latinx have garnered attention in population health research. A number of studies argue that inequalities in educational attainment across these racial/ethnic subpopulations is responsible for an important portion of the racial/ethnic disparities in cognitive and physical health (Garcia et al. 2018; Lin et al. 2014; Schwartz et al. 2004; Thomson et al. 2009; Yaffe et al. 2013). Educational attainment is a modifiable risk factor of cognitive and physical impairment that can be increased through appropriate policy. Therefore, it is important to assess to what extent increasing educational attainment would minimize disparities in cognitive and physical well-being.

\section{Data and Methods}

This study is based on data from the Health and Retirement Study (HRS), a biennial, nationally-representative survey of Americans aged 50 and older along with their spouses of any age. The survey is conducted by the Institute for Social Research at the University of 
Michigan and is funded by National Institute on Aging (NIA U01AG009740) and the Social Security Administration (National Health Services 2019). Additional details of the HRS can be found elsewhere (Fisher and Ryan 2018). We use RAND-HRS longitudinal file 2016 (V2) from 1998-2016, which also includes imputed cognitive scores for self-respondents with missing cognitive data (McCammon et al. 2019). Our analytical sample consists of respondents aged 50 to 100 who have cognitive function and ADL scores in at least two waves. Fewer than one-fifth of $1 \%$ on any of the predictors is missing.

\section{Measures}

\section{Dependent variable}

The dependent variable is a variable with three states: two transient states- joint impairment (cognitively as well as physically impaired) and no joint impairment and one absorbing statedeath. Death is verified through the National Death Index. These three states form the state space of the Markov model.

\section{Physical impairment}

Activities of daily living (ADL), also called basic or physical ADLs, cover the fundamental skills required to fulfill basic/physical needs (Mlinac and Feng 2016). Self-reported ADL is the most commonly-used approach to assess physical functioning ability in research and clinical settings (Bravell et al. 2011). At each wave in the HRS, participants self-report their ability to perform five physical ADL: getting in/out of bed, walking, bathing, dressing, and eating. Respondents reporting having limitations in at least one of these five ADLs are 
classified as 'physically impaired'. Prior investigation has confirmed significant association between subjective evaluation and performance-based evaluation of physical functioning (Bravell et al. 2011).

\section{Cognitive impairment}

We use information from self-respondents and from proxies to define whether a person is cognitively impaired. For self-respondents, the HRS uses a modified version of the Telephone Interview for Cognitive Status (TICS) test. The TICS test scores range from 0 to 27 points, which includes four tasks: immediate ( $0-10$ points) and delayed word recall $(0-10$ points), serial-7s ( $0-5$ points), and counting backward (0-2 points). The cut-points (cognitive impairment, CI: 0-11, and no cognitive impairment, NCI: 12-27) were validated against the Aging Demographics and Memory Study (ADAMS) (Crimmins et al. 2011; Langa et al. 2005), which is a sub-study of the HRS with an in-depth neuropsychological examination.

For the respondents who require a proxy, we follow Langa and Weir to define cognitive health states (Langa et al. 2017). We use a nine-point scale for 1998 that includes proxy's direct assessment of (a) respondent's memory (zero $=$ excellent, four $=$ poor) and (b) respondent's limitations in five instrumental activities of daily living (IADLs): managing money, taking medication, preparing hot meals, using the phone, and shopping for groceries (zero-five). The total score ranges from zero to nine (NCI: zero-two; CI: three-nine). From 2000 onwards, we use an 11-point scale as another measure: (c) interviewer's assessment of the respondent's difficulty completing the interview for cognitive limitations was included (NCI: 0-2; CI: 3-11). The changes in proxy measures in 2000 did not significantly affect our 
results. Similar to the cut points for TICS, the cut points we use for proxies are ADAMS-validated.

\section{Independent variables}

Age is a continuous variable measured in completed years. The HRS reports gender as a binary variable $(1=$ woman). Race/ethnicity categories are Non-Latinx White, Latinx and Non-Latinx Black, US- and foreign-born Latinx, and Others. Because of similar health outcomes of Latinx and Non-Latinx Blacks (Chinn and Hummer 2016), we combine these two subpopulations. Henceforth, we refer to Non-Latinx White as "White" and Latinx and Non-Latinx Black as "Black". We include "Others" in the analyses, but we do not show the results because of its small sample sizes at older ages. Educational categories are less than high school (HS), high school/general equivalency degree (GED)/some college, and associate and above. We combine HS/GED with some college, and Associate with college due to the low mean educational attainment for these earlier cohorts, especially for minority subpopulations, and the small sample size for those with an Associate. We also adjust for the number of cognitive tests taken to account for practice effects (Goldberg et al. 2015), which arise from the repetition of the TICS test across waves.

\section{Statistical analysis}

\section{Multistate modelling}

We calculate the lifetime risk of ever experiencing joint impairment conditional on being not jointly impaired at age 50 and average number of years spent in that state using 
incidence-based discrete-time Markov chain multistate models. This method models transitions among different health states and also captures mortality. The transitions from one health state to the other, e.g., transitions from no joint impairment to joint impairment, are governed by transition probabilities, which are the central inputs to our multistate models. These transition probabilities are then entered into a Markov chain matrix model to calculate the lifetime risk of and life expectancy in joint impairment.

We estimate the models for men and women separately. We estimate two sets of models. In the first set, we include only one predictor (e.g., race/ethnicity). This set of models is used to estimate transition probabilities by that single predictor (e.g., transition probabilities for Latinas). The second set of models is used to model intersections between all the predictors to estimate transition probabilities for all combinations of the predictors. For example, transition probabilities for Latinas with Associate+ education. Practice effect is set to the second interview.

Multistate calculations require specification of a starting state distribution in each of the states at age 50. For each of the subpopulations, we use their own starting state distribution at age 50, e.g., starting state distribution for Whites in the first set of models and for Whites with Associate + education in the second set of models. To avoid small sample noise, starting state distributions are calculated over the age interval 50-60 during 1998-2016. We calculate the $95 \%$ confidence intervals using bootstrapping (500 replications). We use sampling weights from the HRS to account for the complex survey design and non-response. We conduct all analyses using $\mathrm{R}$. 
In the supplementary section, we also present the expectancy estimates for "only cognitively" and "only physically" impaired states, which are currently included in the no joint impairment state. In the main paper, we are focusing on the state of joint impairment - the main focus of this research.

\section{Counterfactual model}

We examine what fraction of the disparities in joint impairment are attributable to educational inequalities by estimating a counterfactual that eliminates racial/ethnic inequalities in the distribution of educational attainment. To calculate these estimates, first, we calculate life expectancy in joint impairment by all combinations of race/ethnicity, nativity, and education. Second, we aggregate these estimates by weighting the educational categories according to Whites' educational distribution, i.e., we combine these estimates by multiplying them with the proportion of Whites in each educational category. In other words, we provide a counterfactual where Blacks and Latinx have the same educational distribution as Whites. This allows us to estimate the racial/ethnic/nativity differences, if they exist, in the years lived in joint impairment absent those which can be attributed to the considerable racial/ethnic inequalities in the distribution of educational attainment. This approach has been applied in a recent study in assessing the benefit of eliminating educational inequalities across racial groups against working poverty (Hale et al. 2021).

\section{Results}

\section{Descriptive statistics}


Table 1 provides the socio-demographic characteristics of the sample during 1998-2016. The total sample size is 37,136 individuals and the analysis is based on 199,930 transitions. Sample sizes for women, Whites, and adults with HS/GED/Some college education are higher than their counterparts. Blacks and foreign- and US-born Latinx are nearly two times more likely to experience a transition to joint impairment than Whites. The lowest educated adults are eight times more likely to experience a transition to joint impairment than the highest educated.

\section{Lifetime risk of joint impairment}

In Panel A (men) and Panel B (women) of Figure 1, we present the lifetime risk of joint impairment for adults who are not jointly impaired at age 50 for total population and by race/ethnicity/nativity, and education separately. Overall, $58 \%(0.58 \times 100)$ of women and $42 \%$ of men aged 50 are predicted to experience joint impairment in their remaining life expectancy. We find considerable disparities across the characteristics under study.

Foreign- and US-born Latinx and Blacks experience greater lifetime risk of joint impairment than Whites, irrespective of gender, and the disparities are substantial. For women, foreign- and US-born Latinas and Blacks experience $31(=83 \%-52 \%)$ percentage point (pp), 20pp, and 17pp higher likelihood of joint impairment than Whites, respectively. For men, the corresponding numbers are $30 \mathrm{pp}, 17 \mathrm{pp}$, and $20 \mathrm{pp}$. The lowest educated women and men experience $27 \mathrm{pp}$ and $32 \mathrm{pp}$ greater lifetime risk of joint impairment, respectively, compared with the highest educated. 
Table 2 shows the lifetime risk for Whites, Blacks, and Latinx subpopulations by educational attainment. Lower educated minorities are the highly disadvantaged subpopulations, especially foreign-born Latinas who experience an $88 \%$ lifetime risk of joint impairment. For each racial/ethnic subpopulation, the likelihood of joint impairment increases as level of educational attainment decreases. For example, for the lowest educated US-born Latinas (and Latinos), the penalty for not having higher education is facing at least 16pp (and 22pp=66\%-44\%) higher lifetime risk of joint impairment. However, racial/ethnic disparities persist at all levels of educational attainment. Notably, the confidence intervals for lifetime risk of US- and foreign-born Latinx with Associate+ education are too wide (reflecting small sample sizes) to draw clear conclusions for these subpopulations. However, in this paper, we are mainly interested in identifying the highly disadvantaged subpopulations, and the estimates for Black and Latinx adults with the lowest education indicate a greater burden of joint impairment for them with a high precision of estimates.

\section{Expectancy in joint impairment at age 50}

Panel A (men) and Panel B (women) of Figure 2 show the average number of years lived in joint impairment at age 50 for total population and by race/ethnicity/nativity, and education separately. On average, women live 1.5 years more jointly impaired compared with men. Compared with Whites, foreign- and US-born Latinx and Black women (men) live 5.4 (2.6), 2.9 (1.1), and 2.5 (1.6) years more in joint impairment. Lowest educated men and women live 2.2 and 3.3 years more in joint impairment than the highest educated, respectively. 
Table 3 shows the life expectancies in joint impairment for all the racial/ethnic subpopulations by various educational levels. In each racial/ethnic subpopulation, the lowest educated have the longest exposure in joint impairment. In particular, Black and Latinx adults with the lowest education are substantially disadvantaged, especially the lowest educated foreign-born Latinx who live longest being jointly impaired (men: 5.0 years, women: 9.6 years), followed by Blacks. Further, the educational gradients are greater for Black and Latinx adults, especially for the two Latinx subpopulations compared with Whites. For instance, having at least an Associate degree decreases the years lived in joint impairment by 8.5 years for foreign-born Latinas and 3.2 years for US-born Latinos. In contrast, White men and women have a difference of only 1.5 years.

\section{Counterfactual: Eliminating disparities in educational attainment}

In Table 4, we present the empirical and counterfactual estimates of joint impairment expectancy for racial/ethnic/nativity subpopulations. For example, 5.2 years in joint impairment for Black women is what we have observed in the empirical scenario. If they had the same educational distribution as White women (counterfactual scenario), they could expect to live 4.3 years in joint impairment - about a year less.

For a better understanding of the results, we show the disparities in Panel A (men) and Panel B (women) of Figure 3, where the bars represent the racial/ethnic/nativity disparities in joint impairment expectancy in the empirical vs. counterfactual scenarios. For instance, in the empirical scenario, Black women live $2.5(=5.2-2.7)$ years more in joint impairment than White women. 
Compared with the empirical scenario, the differences between Whites and Black and Latinx subpopulations' years lived in joint impairment have reduced in the counterfactual scenario. In particular, the two Latinx subpopulations experience the greatest benefit from eliminating the disparities in the distribution of educational attainment. Compared with Black men (women) who experience a reduction of $30 \%$ (36\%), US- and foreign-born Latinos (Latinas) experience a reduction of $72 \%(54 \%)$ and $66 \%(74 \%)$ in the disparities in joint impairment expectancy, respectively.

\section{Discussion}

Being impaired cognitively as well as physically in later life poses serious disadvantages for the affected adults, their family members and caregivers, and for the wider society. Existing research on the burden of disability tends to focus on either cognitive or physical impairment but ignores the aspect of their simultaneous occurrence. Using a nationally representative sample of adults aged 50 and older, this study is the first to assess the burden of joint impairment. This study has three major findings.

First, we estimate the lifetime risk of ever experiencing joint impairment for those who are not jointly impaired at age 50. The lifetime risk of adult women is significantly higher compared with men. This disadvantage is partly attributable to women's advantage in terms of longevity that increases their years of exposure in higher-risk age groups. Blacks, US- and foreign-born Latinx, and lower educated adults have a substantially higher likelihood of joint impairment compared with Whites and the higher educated. 
Second, we measure the burden of joint impairment by estimating how many years an adult aged 50 can expect to live jointly impaired. Men aged 50 have fewer years in joint impairment than women. Compared with older Whites and the higher educated, the number of years lived jointly impaired is significantly higher for older Blacks, US- and foreign-born Latinx and the lower educated.

The combination of two of the primary social determinants of health reveals the large disparities. For instance, the highest educated White men aged 50 can expect to live only one year in joint impairment, whereas the lowest educated foreign-born Latinas aged 50 can expect to live 10 years jointly impaired. Thus, a difference of nine years indicates how dramatic the disparity can be between a vulnerable and an advantaged subpopulation.

Third, there are considerable racial/ethnic inequalities in educational attainment in our sample. For instance, $84 \%$ of Whites have more than a high school education, whereas $35 \%$ Blacks, 44\% US-born and 63\% foreign-born Latinx do not have a high school degree. Our findings reveal that eliminating these inequalities in educational attainment reduce racial/ethnic/nativity disparities in joint impairment considerably. The reduction in the disparities is higher for Latinx subgroups and lower for Blacks. The implication of this exercise include that policies targeted to increase educational attainment could play an important role in reducing racial/ethnic/nativity gaps with Whites, especially for Latinx. However, other factors, for instance, quality of education received (Glymour and Manly 2008), may also be necessary for complete elimination of the disparities. 
Due to the lack of research on joint impairment, direct comparison with previous studies is not possible. Previous research focusing on single impairment also reported a higher burden of disability for Blacks and Latinx, especially for foreign-born Latinx (Garcia et al. 2019; Hayward et al. 2014). Another study found considerable reduction in the disparities in the odds of cognitive impairment for foreign-born Latinx after eliminating educational inequalities (Garcia et al. 2018). However, the risk reduction was lower for Blacks.

The current study provides a detailed overview of the disparities in joint impairment across population subgroups. However, it does not attempt to explain the mechanisms behind these disparities. These are potential areas for further research. There are likely multifaceted explanations. For instance, Blacks and Latinx experience higher rates of chronic morbidities, such as diabetes, than Whites (Ferdinand and Nasser 2015; Whitson et al. 2011), which is associated with poor cognitive and physical health outcomes (Langa et al. 2017; Wong et al. 2013). Prior research indicates that the advantage in disability among the younger foreign-born Latinx over Whites (healthy immigrant effect) does not hold in later life (Melvin et al. 2014). Foreign-born Latinx most often come to the U.S. for employment, which often involves low-paid, physically demanding work (Tienda and Mitchell 2006). The cumulative toll of physically taxing (and sometimes hazardous) jobs, such as in the construction or meat-packing industry (Kochhar 2005), may place them in a particularly vulnerable position in terms of health in later life.

Higher education is associated with better cognitive and physical health (Carmona-Torres et al. 2019; Gobbens 2018). The protective effect of education against 
cognitive decline is usually attributed to highly educated older adults having higher cognitive reserve (Meng and D'Arcy 2012). Cognitive reserve is the ability of the brain to maximize performance through the usage of more efficient brain networks (Stern 2002). Higher educational attainment also influences health positively through better economic and work conditions, higher access to social-psychological resources, and healthier behaviors (Ross and Wu 1995). The disadvantages associated with being Black, Latinx, and lower educated might combine to create an even greater burden for those with intersecting disadvantages. This may partially explain the substantially greater risks as well as longer years in joint impairment for lower educated minorities. Prior evidence also points to a greater health disadvantage for lower educated Blacks compared with highly educated Blacks (Farina et al. 2020; Reuser et al. 2011).

The results may provide some insight into the continuing discourse on the future prospects for morbidity compression or expansion. We observe that for educational categories not accounting for race/ethnicity, as levels of education increase, total life expectancies increase (life expectancy estimates are provided in Table 5); however, life expectancies in joint impairment decrease. Also, for racial/ethnic subpopulations, with increasing educational levels, number of joint impairment years decrease. In other words, advantaged subpopulations have longer life expectancy but shorter jointly impaired years. These findings are promising as there continues to be a debate about whether increasing life expectancy means addition of more morbid years (Steensma et al. 2017). 
Furthermore, our findings may also help to identify the highly vulnerable caregiver subgroups who may need additional support. Disabled adults are provided home care as long as possible by their family members or caregivers, which means caregivers of jointly-impaired adults are particularly vulnerable due to carrying the greatest caregiving burden (Freedman and Spillman 2014; Lepore et al. 2017; Riffin et al. 2017). In particular, Black and Latinx older people are more dependent on their family members for caregiving support compared with White older people (Rote and Moon 2016). According to our findings, Blacks, Latinx and the socio-economically disadvantaged live substantially longer in joint impairment compared with Whites and the highly educated. As a result, their caregivers are at greater risk of poor health outcomes due to the substantial strain arising from the longer duration of joint impairment caregiving. To add, Black caregivers are less likely to use respite services and tend to use fewer formal services for caregiving (Chow et al. 2010; Crist et al. 2009; Parker and Fabius 2020). All these factors raise concern about the caregivers of jointly impaired adults, especially for racial/ethnic minorities, immigrant, and socio-economically disadvantaged subgroups.

As they become increasingly impaired, jointly impaired adults may transition to institutional care. In recent decades, the length of stay in institutional care and the number as well as the percentage of adults using nursing homes has increased for Blacks and Latinx compared with Whites (Feng et al. 2011; Freedman and Spillman 2016). However, such transitions can be particularly disadvantageous for socio-economically disadvantaged subgroups. For instance, nursing home costs have increased in recent decades (Stewart et al. 
2009), and older Blacks and Latinx are more likely to reside in less resourced nursing homes, e.g., with lower staffing ratios, fewer financial resources, and poor care (Fennell et al. 2010; Smith et al. 2007). To add to these disadvantages, almost $16 \%$ of all nursing home facilities have been closed in the United States in the most recent decade, and these closures were mainly in minority communities (Feng et al. 2011).

The US has been experiencing significant population aging, and the population is becoming racially more diverse as well. For example, the share of Latinx and Blacks will increase from $18 \%$ and $13.3 \%$ to $28 \%$ and 15\%, respectively, between 2016 and 2060 (Vespa et al. 2018). In such a situation, the considerably higher burden of joint impairment for minority and lower educated adults, who are also disadvantaged in terms of socio-economic resources, present a serious challenge for policy makers.

This study has some limitations. First, physical activities of daily living are assessed using self-reported information. However, studies have shown a high degree of concordance between self-rated disability and medically diagnosed disability (Wu et al. 2016) and performance-based measures of disability (Bravell et al. 2011). Second, categorizing cognitive function into two standard categories of "no cognitive impairment" and "cognitive impairment" results in a loss of information, but they are a necessary simplification in estimating state expectancies. Third, our findings do not correspond to any particular birth cohort in the HRS. The results reflect the burden of joint impairment if the cognitive and physical health situations during the years 1998-2016 hold throughout the ages 50 and above. 


\section{Conclusion}

In sum, this study provides insight into the burden of the co-occurrence of cognitive and physical impairment and offers evidence of dramatic disparities in this largely ignored component of health impairment in older US population. Our novel findings call attention to the importance of understanding the burden of older age disability from the simultaneous perspective of cognitive and physical impairment. The considerable disparities across subpopulations indicate that the US has a long way to go to attain health equity. Policy with the objective of increasing educational attainment for these minority subpopulations can play a significant role in reducing the disparities in joint impairment, especially for Latinx. Further investigation is required to understand the mechanisms behind these disparities and the reasons for the differential effect of increasing educational attainment on the reduction of disparities across racial/ethnic/nativity subgroups. 


\section{References}

Alzheimer's disease facts and figures. (2021). Alzheimer's and dementia : the journal of the Alzheimer's Association, 17(3), 327-406. https://doi.org/10.1002/alz.12328

Ankuda, C. K., Levine, D. A., Langa, K. M., Ornstein, K. A., \& Kelley, A. S. (2020). Caregiving, Recovery, and Death After Incident ADL/IADL Disability Among Older Adults in the United States. Journal of applied gerontology: the official journal of the Southern Gerontological Society, 39(4), 393-397. https://doi.org/10.1177/0733464819826842

Bravell, M. E., Zarit, S. H., \& Johansson, B. (2011). Self-reported activities of daily living and performance-based functional ability: a study of congruence among the oldest old. European journal of ageing, 8(3), 199-209. https://doi.org/10.1007/s10433-011-0192-6

Carmona-Torres, J. M., Rodríguez-Borrego, M. A., Laredo-Aguilera, J. A., López-Soto, P. J., Santacruz-Salas, E., \& Cobo-Cuenca, A. I. (2019). Disability for basic and instrumental activities of daily living in older individuals. PloS one, 14(7), e0220157. https://doi.org/10.1371/journal.pone.0220157

Caskie, G. I., Sutton, M. C., \& Margrett, J. A. (2010). The relation of hypertension to changes in ADL/IADL limitations of Mexican american older adults. The journals of gerontology. Series B, Psychological sciences and social sciences, 65B(3), 296-305. https://doi.org/10.1093/geronb/gbq001 
Chinn, J. J., \& Hummer, R. A. (2016). Racial Disparities in Functional Limitations Among Hispanic Women in the United States. Research on aging, 38(3), 399-423. https://doi.org/10.1177/0164027515620244

Chow, J. C. C., Auh, E. Y., Scharlach, A. E., Lehning, A. J., \& Goldstein, C. (2010). Types and sources of support received by family caregivers of older adults from diverse racial and ethnic groups. Journal of Ethnic \& Cultural Diversity in Social Work, 19(3), 175-194. https://doi.org/10.1080/15313204.2010.499318

Crichton, S. L., Bray, B. D., McKevitt, C., Rudd, A. G., \& Wolfe, C. D. (2016). Patient outcomes up to 15 years after stroke: survival, disability, quality of life, cognition and mental health. Journal of neurology, neurosurgery, and psychiatry, 87(10), 1091-1098. https://doi.org/10.1136/jnnp-2016-313361

Crimmins, E. M., \& Saito, Y. (2001). Trends in healthy life expectancy in the United States, 1970-1990: gender, racial, and educational differences. Social science \& medicine (1982), 52(11), 1629-1641. https://doi.org/10.1016/s0277-9536(00)00273-2

Crimmins, E. M., Hayward, M. D., \& Saito, Y. (1996). Differentials in active life expectancy in the older population of the United States. The journals of gerontology. Series B, Psychological sciences and social sciences, 51(3), S111-S120. https://doi.org/10.1093/geronb/51b.3.s111.

Crimmins, E. M., Kim, J. K., Langa, K. M., \& Weir, D. R. (2011). Assessment of cognition using surveys and neuropsychological assessment: the Health and Retirement Study and the Aging, 
Demographics, and Memory Study. The journals of gerontology. Series B, Psychological sciences and social sciences, 66 Suppl 1(Suppl 1), i162-i171. https://doi.org/10.1093/geronb/gbr048

Crimmins, E. M., Saito, Y., \& Kim, J. K. (2016). Change in Cognitively Healthy and Cognitively Impaired Life Expectancy in the United States: 2000-2010. SSM - population health, 2, 793-797. https://doi.org/10.1016/j.ssmph.2016.10.007

Crimmins, E. M., Saito, Y., Kim, J. K., Zhang, Y. S., Sasson, I., \& Hayward, M. D. (2018). Educational Differences in the Prevalence of Dementia and Life Expectancy with Dementia: Changes from 2000 to 2010. The journals of gerontology. Series B, Psychological sciences and social sciences, 73(suppl_1), S20-S28. https://doi.org/10.1093/geronb/gbx135

Crist, J. D., McEwen, M. M., Herrera, A. P., Kim, S. S., Pasvogel, A., \& Hepworth, J. T. (2009). Caregiving burden, acculturation, familism, and Mexican American elders' use of home care services. Research and theory for nursing practice, 23(3), 165-180. https://doi.org/10.1891/1541-6577.23.3.165

Farina, M. P., Hayward, M. D., Kim, J. K., \& Crimmins, E. M. (2020). Racial and Educational Disparities in Dementia and Dementia-Free Life Expectancy. The journals of gerontology. Series B, Psychological sciences and social sciences, 75(7), e105-e112. https://doi.org/10.1093/geronb/gbz046

Feng, Z., Fennell, M. L., Tyler, D. A., Clark, M., \& Mor, V. (2011). The Care Span: Growth of racial and ethnic minorities in US nursing homes driven by demographics and possible 
disparities in options. Health affairs (Project Hope), 30(7), 1358-1365. https://doi.org/10.1377/hlthaff.2011.0126

Feng, Z., Lepore, M., Clark, M. A., Tyler, D., Smith, D. B., Mor, V., \& Fennell, M. L. (2011). Geographic concentration and correlates of nursing home closures: 1999-2008. Archives of internal medicine, 171(9), 806-813. https://doi.org/10.1001/archinternmed.2010.492

Fennell, M. L., Feng, Z., Clark, M. A., \& Mor, V. (2010). Elderly hispanics more likely to reside in poor-quality nursing homes. Health affairs (Project Hope), 29(1), 65-73. https://doi.org/10.1377/hlthaff.2009.0003

Ferdinand, K. C., \& Nasser, S. A. (2015). Racial/ethnic disparities in prevalence and care of patients with type 2 diabetes mellitus. Current medical research and opinion, 31(5), 913-923. https://doi.org/10.1185/03007995.2015.1029894

Fisher, G. G., \& Ryan, L. H. (2018). Overview of the Health and Retirement Study and Introduction to the Special Issue. Work, aging and retirement, 4(1), 1-9. https://doi.org/10.1093/workar/wax032

Fratiglioni, L., Wang, H. X., Ericsson, K., Maytan, M., \& Winblad, B. (2000). Influence of social network on occurrence of dementia: a community-based longitudinal study. Lancet (London, England), 355(9212), 1315-1319. https://doi.org/10.1016/S0140-6736(00)02113-9

Freedman, V. A., \& Spillman, B. C. (2014). Disability and care needs among older Americans. The Milbank quarterly, 92(3), 509-541. https://doi.org/10.1111/1468-0009.12076

Freedman, V. A., \& Spillman, B. C. (2016). Active Life Expectancy In The Older US Population, 
1982-2011: Differences Between Blacks And Whites Persisted. Health affairs (Project Hope), 35(8), 1351-1358. https://doi.org/10.1377/hlthaff.2015.1247

Fuller-Thomson, E., Nuru-Jeter, A., Minkler, M., \& Guralnik, J. M. (2009). Black-White disparities in disability among older Americans: further untangling the role of race and socioeconomic status. Journal of aging and health, 21(5), 677-698. https://doi.org/10.1177/0898264309338296

Garcia, M. A., Downer, B., Chiu, C. T., Saenz, J. L., Rote, S., \& Wong, R. (2019). Racial/Ethnic and Nativity Differences in Cognitive Life Expectancies Among Older Adults in the United States. The Gerontologist, 59(2), 281-289. https://doi.org/10.1093/geront/gnx142

Garcia, M. A., Downer, B., Crowe, M., \& Markides, K. S. (2017). Aging and Disability Among Hispanics in the United States: Current Knowledge and Future Directions. Innovation in aging, 1(2), igx020. https://doi.org/10.1093/geroni/igx020

Garcia, M. A., Saenz, J., Downer, B., \& Wong, R. (2018). The role of education in the association between race/ethnicity/nativity, cognitive impairment, and dementia among older adults in the United States. Demographic research, 38, 155-168. https://doi.org/10.4054/DemRes.2018.38.6

Glymour, M. M., \& Manly, J. J. (2008). Lifecourse social conditions and racial and ethnic patterns of cognitive aging. Neuropsychology review, 18(3), 223-254. https://doi.org/10.1007/s11065-008-9064-z 
Gobbens R. J. (2018). Associations of ADL and IADL disability with physical and mental dimensions of quality of life in people aged 75 years and older. PeerJ, 6, e5425. https://doi.org/10.7717/peerj.5425

Goldberg, T. E., Harvey, P. D., Wesnes, K. A., Snyder, P. J., \& Schneider, L. S. (2015). Practice effects due to serial cognitive assessment: Implications for preclinical Alzheimer's disease randomized controlled trials. Alzheimer's \& dementia (Amsterdam, Netherlands), 1(1), 103-111. https://doi.org/10.1016/j.dadm.2014.11.003

Guralnik, J. M., Land, K. C., Blazer, D., Fillenbaum, G. G., \& Branch, L. G. (1993). Educational status and active life expectancy among older blacks and whites. The New England journal of medicine, 329(2), 110-116. https://doi.org/10.1056/NEJM199307083290208

Hajek, A., \& König, H. H. (2016). Longitudinal Predictors of Functional Impairment in Older Adults in Europe--Evidence from the Survey of Health, Ageing and Retirement in Europe. PloS one, 11(1), e0146967. https://doi.org/10.1371/journal.pone.0146967

Hale, J. M., Dudel, C., \& Lorenti, A. (2021). Cumulative Disparities in the Dynamics of Working Poverty for Later Career U.S. Workers (2002-2012). Socius. https://doi.org/10.1177/2378023120987332

Hale, J. M., Schneider, D. C., Gampe, J., Mehta, N. K., \& Myrskylä, M. (2020). Trends in the Risk of Cognitive Impairment in the United States, 1996-2014. Epidemiology (Cambridge, Mass.), 31(5), 745-754. https://doi.org/10.1097/EDE.0000000000001219 
Hale, J. M., Schneider, D. C., Mehta, N. K., \& Myrskylä, M. (2020). Cognitive impairment in the U.S.: Lifetime risk, age at onset, and years impaired. SSM - population health, 11, 100577. https://doi.org/10.1016/j.ssmph.2020.100577

Hankey, G. J., Jamrozik, K., Broadhurst, R. J., Forbes, S., \& Anderson, C. S. (2002). Long-term disability after first-ever stroke and related prognostic factors in the Perth Community Stroke Study, $\quad$ 1989-1990. $\quad$ Stroke, $\quad 33(4), \quad$ 1034-1040. https://doi.org/10.1161/01.str.0000012515.66889.24

Hayward, M. D., Hummer, R. A., Chiu, C. T., González-González, C., \& Wong, R. (2014). Does the Hispanic Paradox in U.S. Adult Mortality Extend to Disability?. Population research and policy review, 33(1), 81-96. https://doi.org/10.1007/s11113-013-9312-7

Heidenreich, P. A., Trogdon, J. G., Khavjou, O. A., Butler, J., Dracup, K., Ezekowitz, M. D., Finkelstein, E. A., Hong, Y., Johnston, S. C., Khera, A., Lloyd-Jones, D. M., Nelson, S. A., Nichol, G., Orenstein, D., Wilson, P. W., Woo, Y. J., American Heart Association Advocacy Coordinating Committee, Stroke Council, Council on Cardiovascular Radiology and Intervention, Council on Clinical Cardiology, ... Council on Cardiovascular Surgery and Anesthesia, and Interdisciplinary Council on Quality of Care and Outcomes Research (2011). Forecasting the future of cardiovascular disease in the United States: a policy statement from the American Heart Association. Circulation, 123(8), 933-944. https://doi.org/10.1161/CIR.0b013e31820a55f5

Kochhar, R. (2008). Latino workers in the ongoing recession: 2007 to 2008. Washington, DC: Pew Hispanic Center. 
Langa, K. M., Larson, E. B., Crimmins, E. M., Faul, J. D., Levine, D. A., Kabeto, M. U., \& Weir, D. R. (2017). A Comparison of the Prevalence of Dementia in the United States in 2000 and 2012. JAMA internal medicine, $177(1)$ $51-58$. https://doi.org/10.1001/jamainternmed.2016.6807

Langa, K. M., Larson, E. B., Karlawish, J. H., Cutler, D. M., Kabeto, M. U., Kim, S. Y., \& Rosen, A. B. (2008). Trends in the prevalence and mortality of cognitive impairment in the United States: is there evidence of a compression of cognitive morbidity?. Alzheimer's \& dementia : the journal of the Alzheimer's Association, 4(2), 134-144. https://doi.org/10.1016/j.jalz.2008.01.001

Langa, K. M., Plassman, B. L., Wallace, R. B., Herzog, A. R., Heeringa, S. G., Ofstedal, M. B., Burke, J. R., Fisher, G. G., Fultz, N. H., Hurd, M. D., Potter, G. G., Rodgers, W. L., Steffens, D. C., Weir, D. R., \& Willis, R. J. (2005). The Aging, Demographics, and Memory Study: study design and methods. Neuroepidemiology, 25(4), 181-191. https://doi.org/10.1159/000087448

Lepore, M., Ferrell, A., \& Wiener, J. M. (2017). Living Arrangements of People with Alzheimer's Disease and Related Dementias: Implications for Services and Supports. Research Summit on Dementia Care: Building Evidence for Services and Supports, (October), $1-14$.

Lièvre, A., Alley, D., \& Crimmins, E. M. (2008). Educational differentials in life expectancy with cognitive impairment among the elderly in the United States. Journal of aging and health, 20(4), 456-477. https://doi.org/10.1177/0898264308315857 
Lin, J., Thompson, T. J., Cheng, Y. J., Zhuo, X., Zhang, P., Gregg, E., \& Rolka, D. B. (2018). Projection of the future diabetes burden in the United States through 2060. Population health metrics, 16(1), 9. https://doi.org/10.1186/s12963-018-0166-4

Lin, S. F., Beck, A. N., \& Finch, B. K. (2014). Black-white disparity in disability among U.S. older adults: age, period, and cohort trends. The journals of gerontology. Series B, $\begin{array}{lllll}\text { Psychological sciences } \quad \text { and } & \text { social }\end{array}$ https://doi.org/10.1093/geronb/gbu010

McCammon, R. J., Fisher, G. G., Hassan, H., Faul, J., Rogers, W., \& Weir, D. (2019). Health and Retirement Study Imputation of Cognitive Functioning Measures: 1992-2016. Survey Research Center, University of Michigan. Retrieved from http://hrsonline.isr.umich.edu/modules/meta/xyear/cogimp/desc/COGIMP9216 dd.pdf

McGrath, R., Al Snih, S., Markides, K., Hackney, K., Bailey, R., \& Peterson, M. (2019). The Burden of Functional Disabilities for Middle-Aged and Older Adults in the United States. The journal of nutrition, health \& aging, 23(2), 172-174. https://doi.org/10.1007/s12603-018-1133-2

Melvin, J., Hummer, R., Elo, I., \& Mehta, N. (2014). Age patterns of racial/ethnic/nativity differences in disability and physical functioning in the United States. Demographic research, 31, 497-510. https://doi.org/10.4054/DemRes.2014.31.17 
Meng, X., \& D'Arcy, C. (2012). Education and dementia in the context of the cognitive reserve hypothesis: a systematic review with meta-analyses and qualitative analyses. PloS one, 7(6), e38268. https://doi.org/10.1371/journal.pone.0038268

Millán-Calenti, J. C., Tubío, J., Pita-Fernández, S., González-Abraldes, I., Lorenzo, T., Fernández-Arruty, T., \& Maseda, A. (2010). Prevalence of functional disability in activities of daily living (ADL), instrumental activities of daily living (IADL) and associated factors, as predictors of morbidity and mortality. Archives of gerontology and geriatrics, 50(3), 306-310. https://doi.org/10.1016/j.archger.2009.04.017.

Mlinac, M. E., \& Feng, M. C. (2016). Assessment of Activities of Daily Living, Self-Care, and Independence. Archives of clinical neuropsychology : the official journal of the National Academy of Neuropsychologists, 31(6), 506-516. https://doi.org/10.1093/arclin/acw049

National Health Services. (2019). Health and Retirement Study (HRS) | National Institute on Aging. Retrieved from https://hrs.isr.umich.edu/welcome-health-and-retirement-study

Ostchega, Y., Harris, T. B., Hirsch, R., Parsons, V. L., \& Kington, R. (2000). The prevalence of functional limitations and disability in older persons in the US: data from the National Health and Nutrition Examination Survey III. Journal of the American Geriatrics Society, 48(9), 1132-1135. https://doi.org/10.1111/j.1532-5415.2000.tb04791.x

Ovbiagele, B., Goldstein, L. B., Higashida, R. T., Howard, V. J., Johnston, S. C., Khavjou, O. A., Lackland, D. T., Lichtman, J. H., Mohl, S., Sacco, R. L., Saver, J. L., Trogdon, J. G., \& American Heart Association Advocacy Coordinating Committee and Stroke Council (2013). 
Forecasting the future of stroke in the United States: a policy statement from the American Heart Association and American Stroke Association. Stroke, 44(8), 2361-2375. https://doi.org/10.1161/STR.0b013e31829734f2

Parker, L. J., \& Fabius, C. D. (2020). Racial Differences in Respite Use among Black and White Caregivers for People Living with Dementia. Journal of aging and health, 32(10), 1667-1675. https://doi.org/10.1177/0898264320951379

Rajan, K. B., Weuve, J., Barnes, L. L., McAninch, E. A., Wilson, R. S., \& Evans, D. A. (2021). Population estimate of people with clinical Alzheimer's disease and mild cognitive impairment in the United States (2020-2060). Alzheimer's \& dementia : the journal of the Alzheimer's Association, 10.1002/alz.12362. Advance online publication. https://doi.org/10.1002/alz.12362

Reuser, M., Willekens, F. J., \& Bonneux, L. (2011). Higher education delays and shortens cognitive impairment: a multistate life table analysis of the US Health and Retirement Study. European journal of epidemiology, 26(5), 395-403. https://doi.org/10.1007/s10654-011-9553-X

Riffin, C., Van Ness, P. H., Wolff, J. L., \& Fried, T. (2017). Family and Other Unpaid Caregivers and Older Adults with and without Dementia and Disability. Journal of the American Geriatrics Society, 65(8), 1821-1828. https://doi.org/10.1111/jgs.14910

Ross, C. E., \& Wu, C. L. (1995). The links between education and health. American sociological review, 719-745. https://doi.org/10.2307/2096319 
Sauvaget, C., Yamada, M., Fujiwara, S., Sasaki, H., \& Mimori, Y. (2002). Dementia as a predictor of functional disability: a four-year follow-up study. Gerontology, 48(4), 226-233. https://doi.org/10.1159/000058355

Schwartz, B. S., Glass, T. A., Bolla, K. I., Stewart, W. F., Glass, G., Rasmussen, M., Bressler, J., Shi, W., \& Bandeen-Roche, K. (2004). Disparities in cognitive functioning by race/ethnicity in the Baltimore Memory Study. Environmental health perspectives, 112(3), 314-320. https://doi.org/10.1289/ehp.6727

Skoog, I., \& Gustafson, D. (2006). Update on hypertension and Alzheimer's disease. Neurological research, 28(6), 605-611. https://doi.org/10.1179/016164106X130506

Smith, D. B., Feng, Z., Fennell, M. L., Zinn, J. S., \& Mor, V. (2007). Separate and unequal: racial segregation and disparities in quality across U.S. nursing homes. Health affairs (Project Hope), 26(5), 1448-1458. https://doi.org/10.1377/hlthaff.26.5.1448

Steensma, C., Loukine, L., \& Choi, B. C. (2017). Evaluating compression or expansion of morbidity in Canada: trends in life expectancy and health-adjusted life expectancy from 1994 to 2010. Portrait de la compression et de l'expansion de la morbidité au Canada : évolution de l'espérance de vie et de l'espérance de vie ajustée en fonction de la santé, 1994 à 2010. Health promotion and chronic disease prevention in Canada : research, policy and practice, 37(3), 68-76. https://doi.org/10.24095/hpcdp.37.3.02

Stern Y. (2002). What is cognitive reserve? Theory and research application of the reserve concept. Journal of the International Neuropsychological Society : JINS, 8(3), 448-460. 
Stewart, K. A., Grabowski, D. C., \& Lakdawalla, D. N. (2009). Annual expenditures for nursing home care: private and public payer price growth, 1977 to 2004. Medical care, 47(3), 295-301. https://doi.org/10.1097/MLR.0b013e3181893f8e

Rote, S. M., \& Moon, H. (2018). Racial/Ethnic Differences in Caregiving Frequency: Does Immigrant Status Matter?. The journals of gerontology. Series B, Psychological sciences and social sciences, 73(6), 1088-1098. https://doi.org/10.1093/geronb/gbw106

Suthers, K., Kim, J. K., \& Crimmins, E. (2003). Life expectancy with cognitive impairment in the older population of the United States. The journals of gerontology. Series B, Psychological sciences and social sciences, 58(3), S179-S186. https://doi.org/10.1093/geronb/58.3.s179

Tienda, M., Mitchell, F., \& National Research Council (US) Panel on Hispanics in the United States (Eds.). (2006). Multiple Origins, Uncertain Destinies: Hispanics and the American Future. National Academies Press (US).

Ferrucci, L., Guralnik, J. M., Salive, M. E., Pahor, M., Corti, M. C., Baroni, A., \& Havlik, R. J. (1996). Cognitive impairment and risk of stroke in the older population. Journal of the American $\quad$ Geriatrics $\quad$ Society, $\quad 44(3), \quad$ 237-241. https://doi.org/10.1111/j.1532-5415.1996.tb00908.x

Vespa, J., Armstrong, D. M., and Medina, L. (2018). Demographic turning points for the United States: Population projections for 2020 to 2060. Washington, DC: US Department of Commerce, Economics and Statistics Administration, US Census Bureau. Retrieved from https://www.census.gov/content/dam/Census/library/publications/2020/demo/p25-1144.pdf 
Wang, S., Phillips, D., \& Lee, J. (2021). Disability prevalence in midlife (aged 55-65 years): Cross-Country comparisons of gender differences and time trends. Women's midlife health, 7(1), 1. https://doi.org/10.1186/s40695-020-00061-0

Whitson, H. E., Hastings, S. N., Landerman, L. R., Fillenbaum, G. G., Cohen, H. J., \& Johnson, K. S. (2011). Black-white disparity in disability: the role of medical conditions. Journal of the American $\quad$ Geriatrics $\quad$ Society, $\quad$ 59(5), $\quad$ 844-850. https://doi.org/10.1111/j.1532-5415.2011.03401.x

Wong, E., Backholer, K., Gearon, E., Harding, J., Freak-Poli, R., Stevenson, C., \& Peeters, A. (2013). Diabetes and risk of physical disability in adults: a systematic review and meta-analysis. The lancet. Diabetes \& endocrinology, 1(2), 106-114. https://doi.org/10.1016/S2213-8587(13)70046-9

World Health Organization. (2017). Global health observatory (GHO) data. Life expectancy. Retrived from https://apps.who.int/gho/data/node.main.688

Wu, L. W., Chen, W. L., Peng, T. C., Chiang, S. T., Yang, H. F., Sun, Y. S., Chan, J. Y., \& Kao, T. W. (2016). All-cause mortality risk in elderly individuals with disabilities: a retrospective $\begin{array}{lllll}\text { observational study. } & \text { BMJ }\end{array}$ https://doi.org/10.1136/bmjopen-2016-011164

Yaffe, K., Falvey, C., Harris, T. B., Newman, A., Satterfield, S., Koster, A., Ayonayon, H., Simonsick, E., \& Health ABC Study (2013). Effect of socioeconomic disparities on incidence 
of dementia among biracial older adults: prospective study. BMJ (Clinical research ed.), 347, f7051. https://doi.org/10.1136/bmj.f7051

Zaninotto, P., Batty, G. D., Stenholm, S., Kawachi, I., Hyde, M., Goldberg, M., Westerlund, H., Vahtera, J., \& Head, J. (2020). Socioeconomic Inequalities in Disability-free Life Expectancy in Older People from England and the United States: A Cross-national Population-Based Study. The journals of gerontology. Series A, Biological sciences and medical sciences, 75(5), 906-913. https://doi.org/10.1093/gerona/glz266

Zsembik, B. A., Peek, M. K., \& Peek, C. W. (2000). Race and ethnic variation in the disablement process. Journal of aging and health, $12(2)$, 229-249. https://doi.org/10.1177/089826430001200205 
Tables

Table 1 Descriptive characteristics of the sample

\begin{tabular}{|c|c|c|c|c|}
\hline & Individuals $\%$ & Transitions & $\%$ & $\begin{array}{c}\% \text { transition } \\
\text { to joint } \\
\text { impairment }\end{array}$ \\
\hline Overall & 37,136100 & 199,930 & 100 & 17 \\
\hline Men & $16,47544.4$ & 85,569 & 42.7 & 6 \\
\hline Women & $20,66155.6$ & 114,361 & 57.3 & 8 \\
\hline White & $24,33665.5$ & 141,361 & 70.7 & 6 \\
\hline Black & 707219.0 & 33,054 & 16.5 & 11 \\
\hline US-born Latinx & 17034.6 & 8,360 & 4.2 & 10 \\
\hline Foreign-born Latinx & 26867.2 & 11,857 & 5.9 & 11 \\
\hline Less than high school & $8,98624.2$ & 46,945 & 23.5 & 16 \\
\hline $\mathrm{HS}^{\mathrm{a} / \mathrm{GED}^{\mathrm{b}} / \text { Some college }}$ & $18,88250.9$ & 103,939 & 52.0 & 5 \\
\hline Associate + & $9,26825.0$ & 49,046 & 24.5 & 2 \\
\hline
\end{tabular}


Table 2 Lifetime risk (in \%) of joint impairment for interactions of gender, race/ethnicity/nativity, and education in the US, 1998-2016, with $95 \%$ confidence interval (CI)

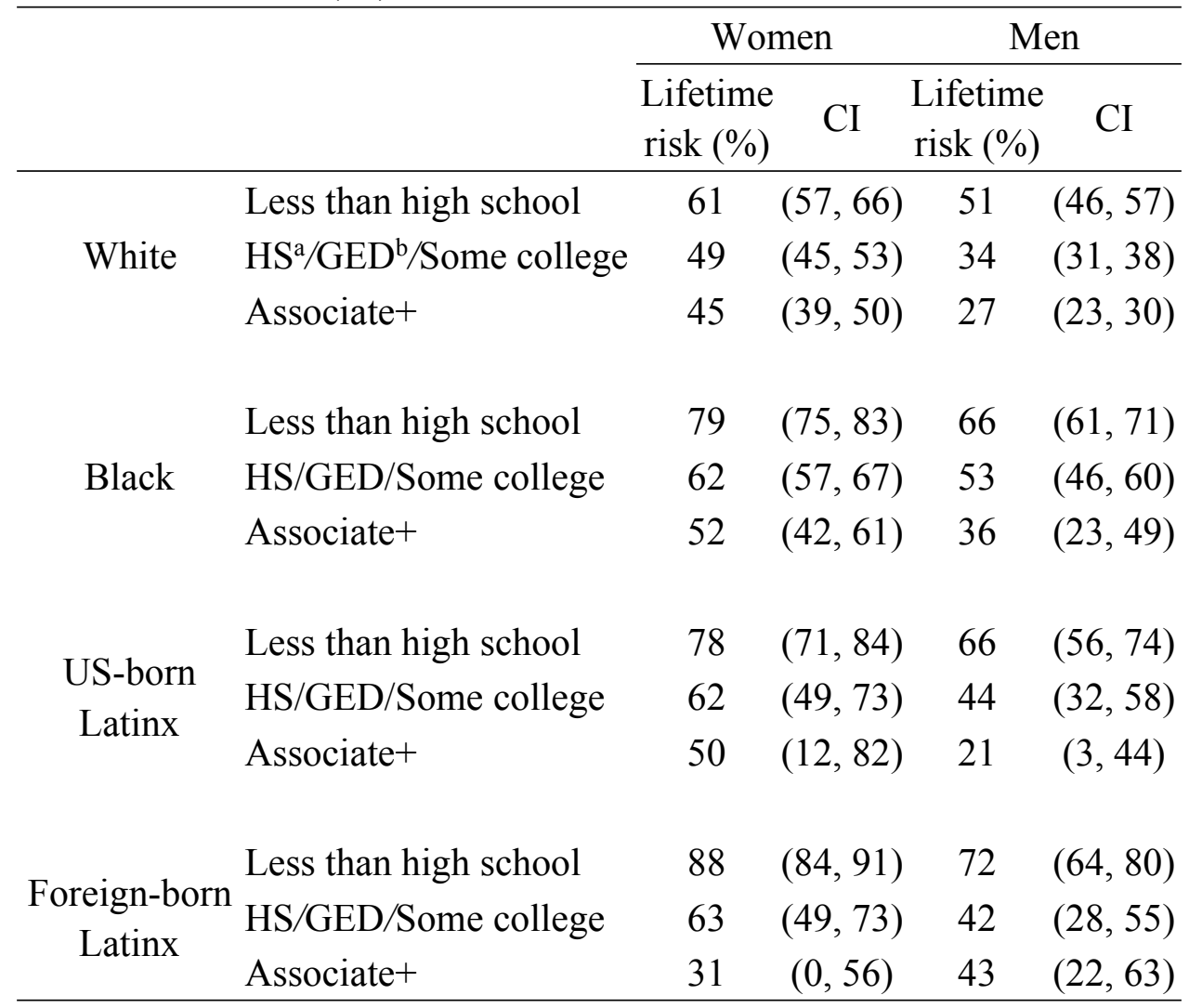

\section{${ }^{a}$ High School}

${ }^{\mathrm{b}}$ General equivalency degree

Source: 1998-2016 Health and Retirement Study 
Table 3 Life expectancies in joint impairment at age 50 for interactions of gender, race/ethnicity/nativity, and education in the US, 1998-2016, with 95\% confidence interval (CI)

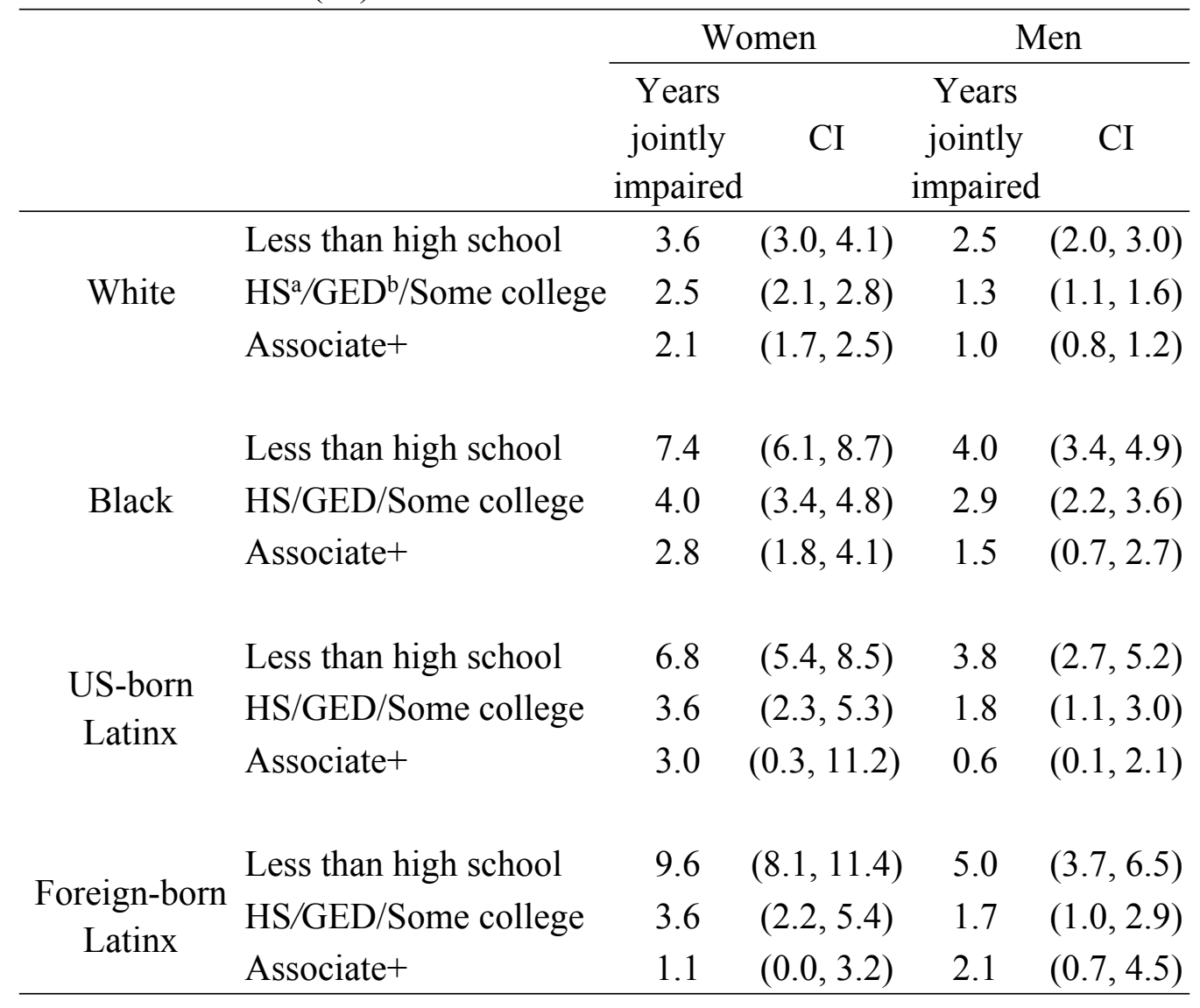

${ }^{a}$ High School

${ }^{\mathrm{b}}$ General equivalency degree

Source: 1998-2016 Health and Retirement Study 
Table 4 Results showing how eliminating racial/ethnic inequalities in educational attainment would reduce racial/ethnic disparities in joint impairment, measured in number of years

\begin{tabular}{lcc}
\hline & \multicolumn{2}{c}{ Years } \\
\cline { 2 - 3 } & Men & Women \\
\hline White empirical & 1.5 & 2.7 \\
Black empirical & 3.1 & 5.2 \\
Black counterfactual & 2.6 & 4.3 \\
& & \\
US-born Latinx empirical & 2.6 & 5.6 \\
US-born Latinx counterfactual & 1.8 & 4.1 \\
& & \\
Foreign-born Latinx empirical & 4.1 & 8.1 \\
Foreign-born Latinx counterfactual & 2.4 & 4.1 \\
\hline
\end{tabular}

Source: 1998-2016 Health and Retirement Study 
Table 5 Total life expectancies at age 50 with $95 \%$ confidence interval (CI)

\begin{tabular}{lcccc}
\hline & \multicolumn{4}{c}{ Years } \\
\cline { 2 - 5 } & Men & $95 \%$ CI & Women & $95 \%$ CI \\
\hline Total & 28.4 & $(27.5,29.3)$ & 32.9 & $(31.8,33.8)$ \\
White & & & & \\
Black & 28.8 & $(27.8,29.7)$ & 33.3 & $(32.2,34.3)$ \\
US-born Latinx & 25.6 & $(24.2,26.9)$ & 29.7 & $(28.3,31.0)$ \\
Foreign-born Latinx & 26.8 & $(24.7,28.9)$ & 34.0 & $(31.9,35.9)$ \\
& 31.9 & $(30.0,33.7)$ & 36.3 & $(34.7,37.8)$ \\
Less than high school & 25.3 & $(24.1,26.4)$ & 29.6 & $(28.4,30.8)$ \\
HS $/$ GED ${ }^{\mathrm{b}} /$ Some college & 28.0 & $(27.1,29.0)$ & 33.2 & $(32.0,34.1)$ \\
Associate+ + & 31.4 & $(30.3,32.5)$ & 35.3 & $(34.1,36.4)$ \\
\hline
\end{tabular}

${ }^{a}$ High School

${ }^{\mathrm{b}}$ General equivalency degree

Source: 1998-2016 Health and Retirement Study 
Figures

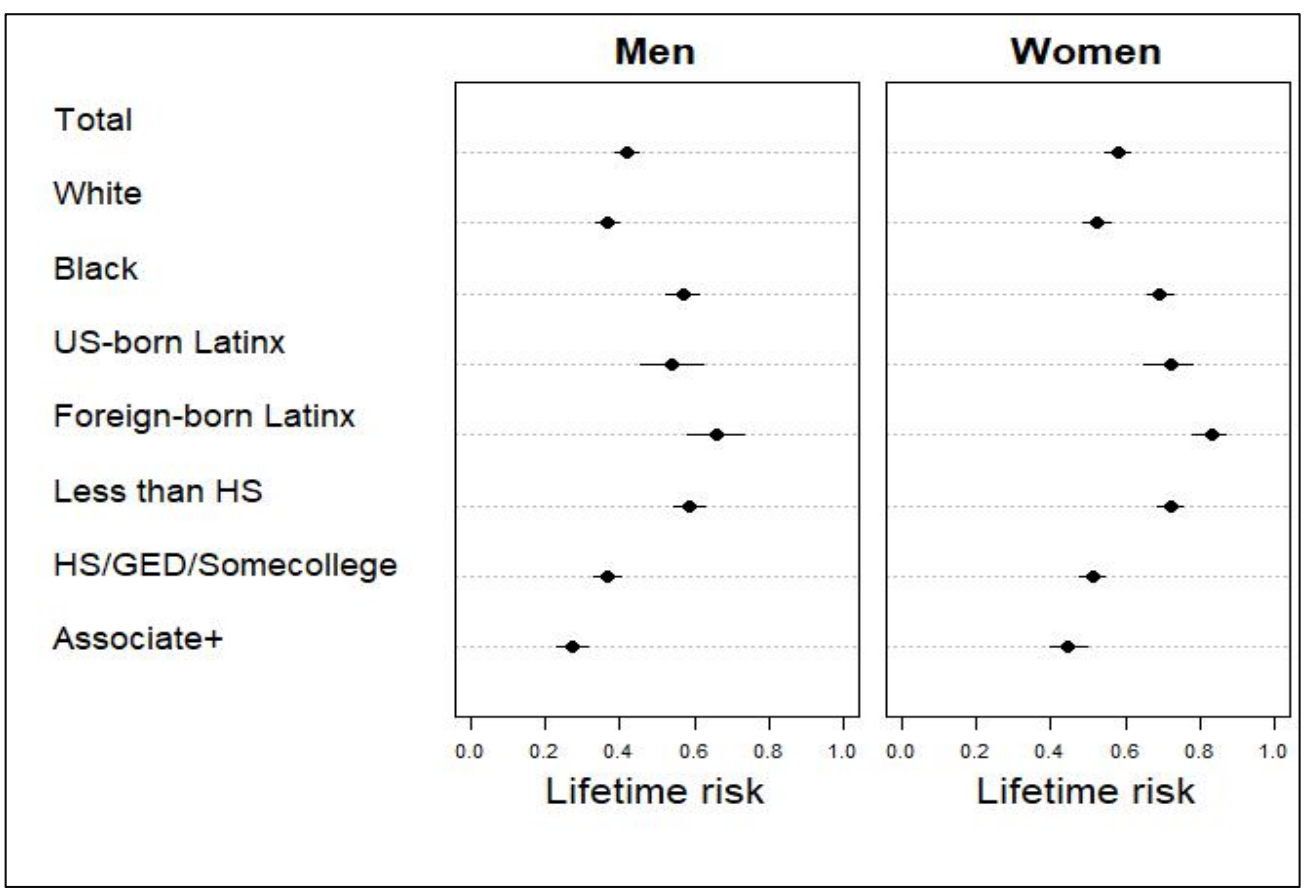

Fig. 1 Lifetime risk of joint impairment for total men (Panel A) and women (Panel B) population and by race/ethnicity/nativity, and education in the US, 1998-2016.

Notes: A lifetime risk of 0.83 can also be expressed in percentage (83\%). HS and GED are abbreviated versions of high school and general equivalency degree, respectively.

Source: 1998-2016 Health and Retirement Study 


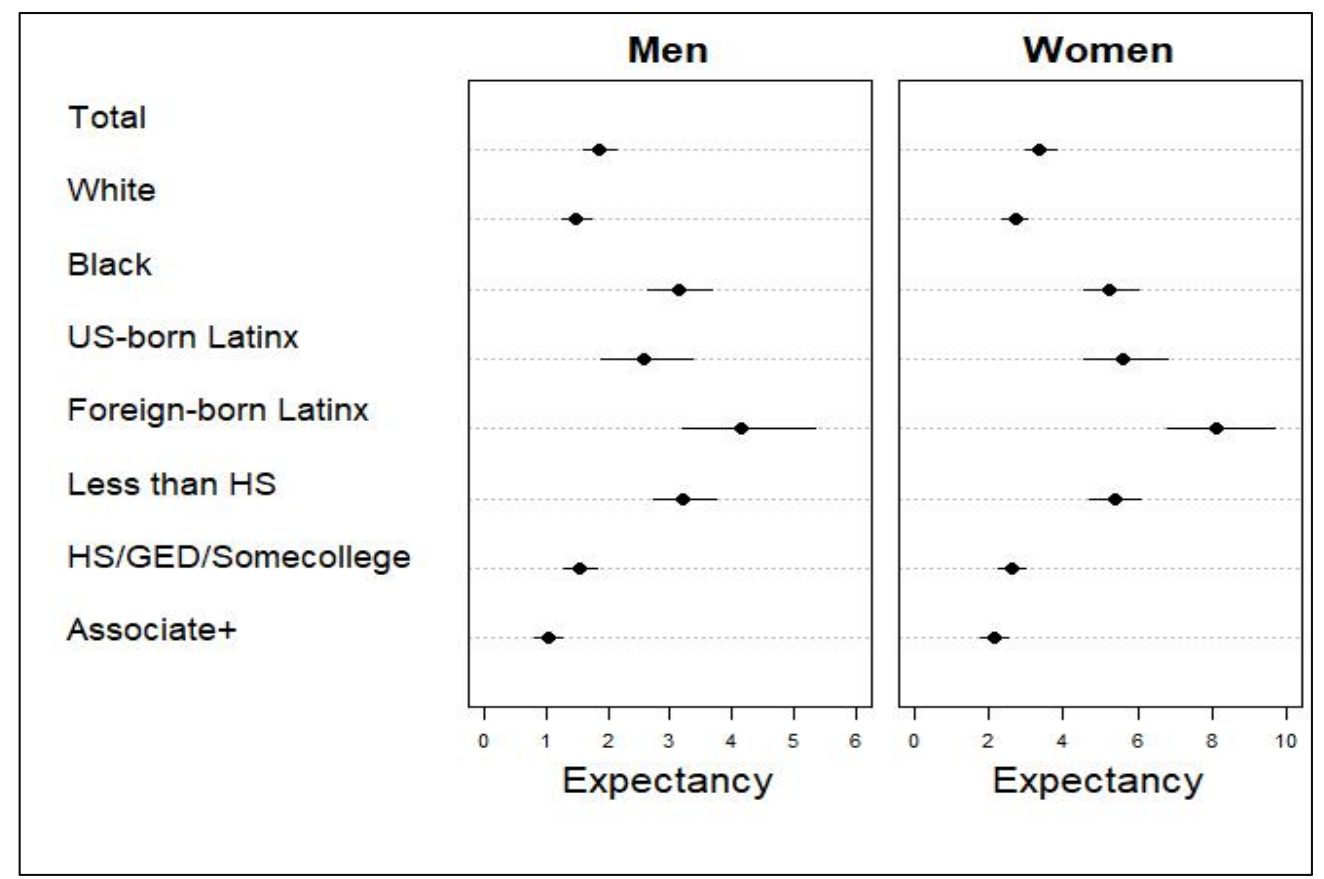

Fig. 2 Expectancy in joint impairment at age 50 for total men (Panel A) and women (Panel B) population and by race/ethnicity/nativity, and education in the US, 1998-2016.

Notes: HS and GED are abbreviated versions of high school and general equivalency degree, respectively.

Source: 1998-2016 Health and Retirement Study 


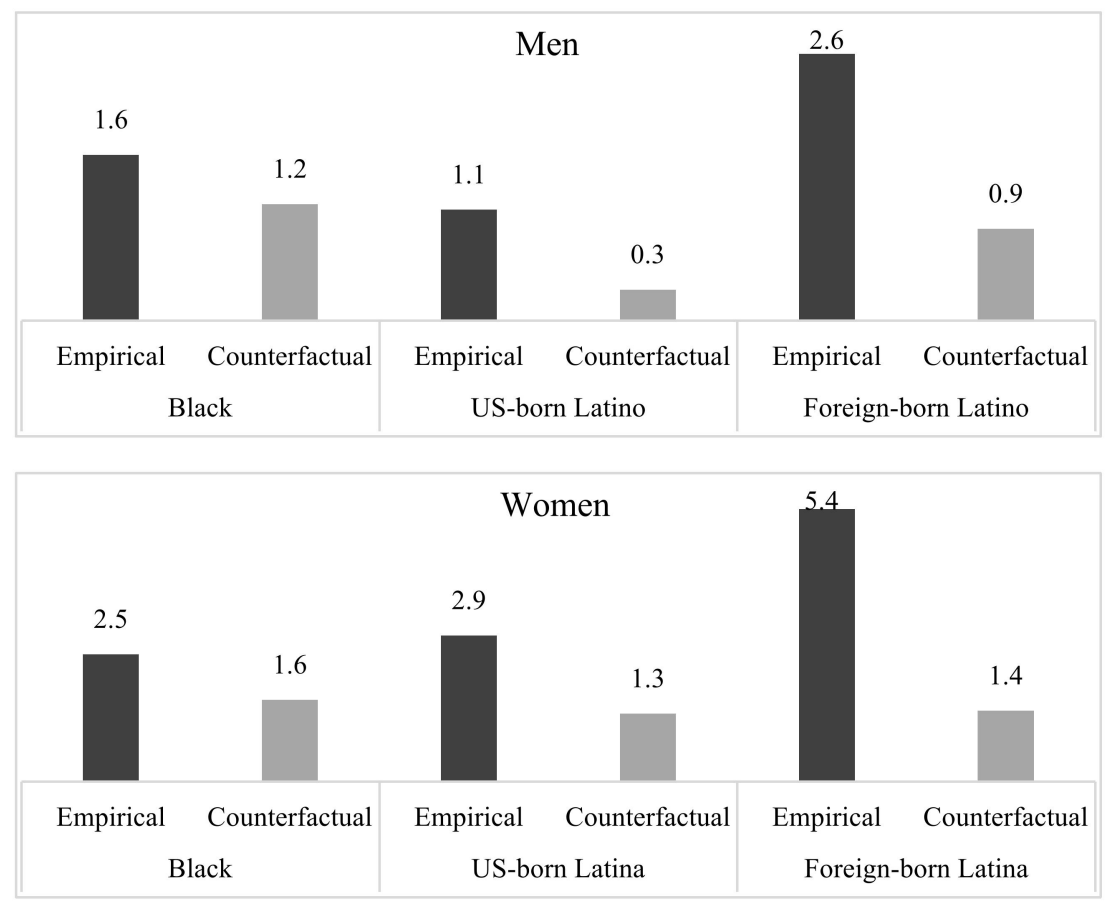

Fig. 3 Racial/ethnic/nativity disparities in joint impairment years in empirical vs. counterfactual scenario for men (Panel A) and women (Panel B) in the US, 1998-2016.

Source: 1998-2016 Health and Retirement Study 
Figure titles

Fig. 1 Lifetime risk of joint impairment for total men (Panel A) and women (Panel B) population and by race/ethnicity/nativity, and education in the US, 1998-2016.

Fig. 2 Expectancy in joint impairment at age 50 for total men (Panel A) and women (Panel B) population and by race/ethnicity/nativity, and education in the US, 1998-2016.

Fig. 3 Racial/ethnic/nativity disparities in joint impairment years in empirical vs. counterfactual scenario for men (Panel A) and women (Panel B) in the US, 1998-2016. 


\section{Supplementary materials}

In the main paper, we focused on the joint cognitive and physical impairment which was the primary focus of this paper. In this supplementary section, we present the expectancy estimates in "only cognitively" and "only physically" impaired states in Table 6 and Table 7.

Table 6 Life expectancies in "only cognitively" and "only physically" impaired states at age 50 by race/ethnicity/nativity, and education in the US, 1998-2016, Men

\begin{tabular}{lcc}
\hline & Only Cognitive impairment & Only Physical impairment \\
\hline Total & 3.3 & 2.4 \\
White & 2.6 & 2.4 \\
Black & 5.9 & 2.2 \\
US born Latinx & 5.4 & 2.2 \\
Foreign born Latinx & 6.3 & 3.4 \\
& & \\
Less than high school & 6.8 & 2.4 \\
HS $/$ GED $/$ Some college & 2.8 & 2.8 \\
Associate+ & 1.5 & 2.2 \\
\hline
\end{tabular}

${ }^{a}$ High School

${ }^{\mathrm{b}}$ General equivalency degree

Source: 1998-2016 Health and Retirement Study 
Table 7 Life expectancies in "only cognitively" and "only physically" impaired states at age 50 by race/ethnicity/nativity, and education in the US, 1998-2016, Women

\begin{tabular}{|c|c|c|}
\hline & Only Cognitive impairment & Only Physical impairment \\
\hline Total & 3.6 & 3.5 \\
\hline White & 2.7 & 3.3 \\
\hline Black & 6.0 & 3.6 \\
\hline US born Latinx & 7.7 & 3.6 \\
\hline Foreign born Latinx & 7.3 & 4.8 \\
\hline Less than high school & 6.8 & 3.9 \\
\hline $\mathrm{HS}^{\mathrm{a}} / \mathrm{GED}^{\mathrm{b}} /$ Some college & 2.9 & 3.6 \\
\hline Associate+ & 1.8 & 3.3 \\
\hline
\end{tabular}

${ }^{\mathrm{a}}$ High School

${ }^{\mathrm{b}}$ General equivalency degree

Source: 1998-2016 Health and Retirement Study 